\title{
Un aporte de Carlos Guastavino y Lima Quintana al mundo de la Nueva Canción argentina
}

\author{
Silvina Luz Mansilla (Facultad de Filosofía y Letras, Universidad de Buenos Aires, Argentina). \\ silman@filo.uba.ar
}

\begin{abstract}
Resumen: El artículo se refiere a la canción Hermano compuesta por el músico Carlos Guastavino sobre una poesía de Hamlet Lima Quintana. Dedicada al editor Rómulo Lagos, fue grabada por Mercedes Sosa en 1966. Incluida como pista inicial del disco de la cantante tucumana al cual le dio su nombre, la canción constituye una evidencia de la simpatía del compositor con los postulados centrales del Nuevo Cancionero argentino. El trabajo comprende una aproximación a la temática del poema, el análisis musical de la partitura, la puesta en contexto de las circunstancias de composición y difusión y la descripción de la versión grabada por Mercedes Sosa. Aplicando la noción "mundos del arte" de Howard BECKER (1982), se interpreta la red de personas ligadas a la editorial Lagos como un tejido cooperativo que funcionó con eficacia hasta mediados de la década de 1970. Un esbozo del contexto posterior, signado por la censura, permite inferir algunos factores que incidieron en el quiebre de esa red de colaboraciones. Aunque respecto de Guastavino, se habla aquí de vinculación y no de pertenencia.
\end{abstract}

Palabras clave: Carlos Guastavino, Nuevo cancionero, censura, Mercedes Sosa, canción popular.

\section{Carlos Guastavino and Lima Quintana's contribution to the world of the Argentinean New Song}

Abstract: Study about the song Hermano by Argentinean composer Carlos Guastavino written after a poem by Hamlet Lima Quintana. Dedicated to the editor Rómulo Lagos, the song was recorded by the Argentinean singer Mercedes Sosa in 1966. Included as the first track in that record (to which it gave its name), the song constitutes an evidence of the composer's sympathy with the central postulates of the Argentinean New Song. This paper's perspective integrates the poem's subject, the score's musical analysis, the study of the context concerning with the composition and spreading circumstances and the description of the performance recorded by Mercedes Sosa. Applying the notion of "art worlds" by Howard BECKER (1982), we interpret the persons net connected with Lagos publishing, as a co-operative and interwoven fabric that effectively worked until the mid 1970s. A sketch of the following context, signed by the Argentinean censorship, reveals some factors that had influence on the crack of that collaborative net. Although it concerns Guastavino, our approach is concerned with connection and not to belonging.

Keywords: Carlos Guastavino, Argentinean New Song, censorship, Mercedes Sosa, folk song.

\section{1- Introducción ${ }^{1}$}

El 23 de junio de 1966 la revista argentina Confirmado publicó una nota referida a la cantante tucumana Mercedes Sosa, bajo el título Folklore: ese camino difícil. ${ }^{2}$ Hacía poco tiempo -apenas algo más de un año-que ella protagonizaba el mayor éxito como la voz femenina del boom del folclore. Su momento clave de consagración artística, ocurrido en enero de 1965 en el Festival de la localidad cordobesa de Cosquín, había consistido en unos pocos minutos de actuación -escasos pero gloriosos- cedidos por Jorge Cafrune en el escenario mayor
(PORTORRIC0, 2004, p.355). Ahora en cambio, faltaba poco tiempo, apenas días, para el comienzo de una fase nada gloriosa de la historia de Argentina: el 28 de junio de ese año asumiría la presidencia de la nación el General Juan Carlos Onganía. Se iniciaría así una etapa, al decir de Luis Alberto ROMERO (2001), de shock autoritario, en la que el rumbo de la Nueva Canción emprendería en ese país un período de lucha por imponerse, emergiendo desde algunos espacios recoletos, a la sombra de una persistente censura. ${ }^{3}$ 
El segundo disco de Mercedes Sosa (1935-2009), titulado Hermano, apareció hacia fines de $1966 .^{4}$ Postulo aquí que su primera pista, que contenía la canción homónima de Hamlet Lima Quintana (1923-2002) y Carlos Guastavino (1912-2000), constituye una significativa evidencia de la simpatía del compositor santafesino con los postulados centrales del manifiesto del Nuevo Cancionero y por ende, con su línea de pensamiento. Interpreto las circunstancias relacionadas con la producción y circulación de la canción Hermano, dedicada al editor de música Rómulo Lagos. Si bien no se conoce que el músico haya adoptado públicamente actitudes comprometidas en el campo de la política, recrear aquel contexto en el que se movió durante la década de 1960 y conocer su manera de relacionarse con los integrantes del Nuevo Cancionero, ayuda a comprender la disminución que se produce en la difusión de su música en los años de la última dictadura militar argentina.

El marco que encuentro apropiado para esta reflexión es la noción de mundos del arte de Howard BECKER (1982). Verdadera red de colaboración que conforma un tejido complejísimo de intereses de todo orden en el que se engloban no solo los artistas, sino también los consumidores, mecenas y críticos, el mundo de la Nueva Canción, según mi análisis, aproximó a la música de Guastavino a los ámbitos de la militancia progresista. ${ }^{5}$

El trabajo comprende una aproximación a la temática del poema, el análisis musical de la partitura, la puesta en contexto de la versión grabada por Mercedes Sosa y un esbozo sobre algunos factores que pudieron incidir en la menor circulación durante fines de los años 70. Desde el punto de vista metodológico, apelo al contraste entre la información obtenida de algunas fuentes hemerográficas con aquella procedente de entrevistas cualitativas, en las que he empleado herramientas de historia oral.

\section{2- Lima Quintana, Mercedes Sosa y Guas- tavino}

Las fuentes orales consultadas confirmaron la sospecha inicial: fue el editor Rómulo Lagos quien, como en otros casos, concertó la presentación recíproca entre Carlos Guastavino y el poeta a musicalizar. ${ }^{6}$ A la primera colaboración de 1963, que aquí estudiamos, le siguieron después algo más de una decena de piezas en conjunto: El único camino en 1964, Pampamapa en 1965 y finalmente el ciclo de nueve canciones titulado Edad del asombro, en 1968, referido a la infancia y al pasaje del niño a la adolescencia.

Hamlet Lima Quintana, poeta, cantor, autor y también, compositor, ${ }^{7}$ comenzó a tener difusión en el ámbito de la canción de raíz folclórica en Buenos Aires a principios de 1962, al grabar su zamba La amanecida, que había compuesto nueve años antes con Mario Arnedo Gallo. Conoció en 1963 a Armando Tejada Gómez y otros referentes de la Nueva Canción argentina e inmediatamente comprendió que compartían similitud de temáticas, objetivos y estilo literario. ${ }^{8}$
Ubicado en la década de 1960 en lo que Sergio Pujol denomina un "mundo poético coloquial y directo", Lima Quintana encarnaba la imagen del juglar, que había vuelto a aparecer con fuerza y que se expresaba a través de un estilo poético de corte popular, deseoso de sonido, de musicalización (PUJOL, 2002, p.133135). Unos meses antes de la grabación de Hermano, se había dado a conocer su célebre Zamba para no morir (con música de Norberto Ambrós y Néstor Rosales), ${ }^{9}$ en la voz de Mercedes Sosa. Incluida en su primer disco larga duración titulado Yo no canto por cantar, fue sin duda uno de las piezas consagratorias del poeta, y de la intérprete. ${ }^{10}$ No es difícil suponer entonces que el disco Hermano, separado por pocos meses del anterior, pasara algo opacado por el rápido reconocimiento del público que alcanzó la Zamba para no morir. Tampoco es antojadizo pensar que haya sido el género el que incidió en su mayor popularización, puesto que como se ha dicho, el "boom del folclore" fue en gran medida el "boom de la zamba"."1

La admiración de Lima Quintana por la voz de la cantante tucumana, ha quedado asi descripta:

\begin{abstract}
"[...] Mercedes no era entonces conocida. Era una ignorada cantora que nos ponia la piel de gallina cuando largaba la voz. Recuerdo que yo bajaba la escalera [se refiere a la entrada de la peña El Hormiguero] cuando escuché: 'Romperá la tarde mi voz/ hasta el eco de ayer...' Bajé tres escalones más... y continuó: 'Voy quedándome sola al final/ muerta de sed/ harta de andar/ pero sigo creciendo en el sol/ vivo...' Recién cuando bajé el último escalón pude ver, sentados junto a una mesa, a Mercedes y al Monchito [Ramón Miérez] ensayando la Zamba para no morir. Era la primera vez que la escuchaba cantada. Todavía me duele la felicidad..." (LIMA QUINTANA, 1994, p.15)
\end{abstract}

\section{3- Poesía, música e ideologías}

El texto de Hermano aparece ligado a la forma de expresión poética de corte popular cultivada en Argentina por esos años. ${ }^{12}$ (Ex.1) Sutilmente contestatario, con una métrica predominantemente octosílaba en las estrofas de cuatro versos, dice:

Fijate hermano cómo vas cantando, Toda la tierra te escucha conmigo.

Del surco hasta el cañadón,

Del viento hasta la madera,

Del tiempo hasta la ternura de la vida verdadera.

Porque es preciso tener

Un corazón derramado

Jirones de sueños viejos

que van quedando olvidados.

Fíjate hermano cómo vas cantando, Toda la tierra te escucha conmigo.

Del grito hasta la oración, del fuego hasta la memoria que el hombre en dolor viviente canta sangre de su historia. 
Y cuando quede al final

tu corazón silencioso

serás un pueblo sintiendo

por un cantor milagroso.

Fíjate hermano cómo vas cantando, Toda la tierra te escucha conmigo.

Ex.1. 'Hermano'. Poema de Hamlet Lima Quintana.

Sugiere el poema la idea de una hermandad universal a la cual se podría acceder mediante el canto: el cantor, constituido en la arcilla o el elemento aglutinante de los pueblos, realizaría ese milagro al convertirse en el portavoz de sus necesidades, penas e historias. ${ }^{13}$ El contenido de este texto se podría encuadrar claramente en el tipo de canciones "políticas" "con sentido amplio y valórico," como Ilama Eduardo CARRASCO PIRARD (1999, p.68) al nutrido repertorio con temáticas en las que se ponen en juego valores sociales en la música popular chilena de la misma década.

En relación con esto, Omar CORRADO (2001, p.18) ha sugerido ya, levemente, una posible pertenencia de Guastavino a la izquierda, cuando expresa que "no es fortuito" que el compositor se interesara por musicalizar algunos poemas de Rafael Alberti, Pablo Neruda y Luis Cernuda. Por mi parte, de las numerosas comunicaciones personales y entrevistas mantenidas con él a lo largo de varios años, no emanó con precisión que hubiera adherido a alguno de los partidos políticos de esa tendencia o que hubiera estado formalmente afiliado. Era notable no obstante, como lo han resaltado también otras personas que lo conocieron y trataron, su denodada búsqueda por la valoración del hombre, su defensa de la libertad de expresión y su enorme sensibilidad para con los desposeídos. ${ }^{14}$

Entrevistados por Marcela GONZÁLEZ (1999, p.83), dos músicos argentinos muy allegados al compositor -el guitarrista Vicente Elías y la pianista Elsa Puppulo-refrendaron estas ideas hacia fines de los 90. Elias afirmó que "[...] era una persona muy democrática, con gran sentido de la libertad y de valoración del ser humano [lo cual] en épocas pasadas [...] equivalía a ser comunista." Puppulo, por su parte, dijo que "[...] se armó gran confusión con la gira que concretó por la antigua U.R.S.S. y China. Inmediatamente fue tildado de comunista [...]; bastó esa referencia para descalificarlo."

Con respecto a Lima Quintana, afiliado al partido comunista hasta sus últimos días, resulta de interés rescatar aquí sus explicaciones en torno a la ligazón entre poesía y música. Escribió:

\footnotetext{
"No establezco diferencias cuando escribo una poesia para ser cantada, con la poesía que escribo para ser leída. Son dos formas diferentes con un mismo mensaje, una misma intención y un idéntico fin: entablar el diálogo con los otros, los semejantes. Además, no se debe echar al olvido que la música es el vehículo natural de la poesía." (LIMA QUINTANA, 1994, p.31)
}

Esta actitud de defensa, tanto de la posibilidad de acercamiento a los otros a través de la poesía como de la existencia de una conexión 'natural' entre música y poesía, permitió a Lima Quintana explicar la causa de su situación de poeta ignorado por la elite literaria y por la crítica argentina. Según comenta en su libro, la calificación de 'poeta marginal' con que se lo rotuló en las cátedras universitarias de literatura argentina durante la dictadura de Onganía, radicó en que escribía canciones. El resto de su producción, editada en libros, no fue tomada en cuenta. ${ }^{15}$

\section{4- Aproximación analítica}

La partitura de Guastavino recurre a un entorno proveniente de la cifra y de la milonga, posiblemente por la indicación de 'canción al sur' realizada por Lima Quintana, que refiere en forma rotunda al folclore sureño. ${ }^{16} \mathrm{La}$ aparición del ritmo de milonga se da en las cuartetas octosilábicas prefiriendo el músico para los dos versos que enmarcan simétricamente comienzo, mitad y cierre del poema, un pasaje enfático donde el canto, en ritmo casi libre, entona en el estilo de la cifra, el mensaje principal allí contenido "sin rigor, casi recitado" (Ex.2). ${ }^{17}$

Quasi improvisada, la introducción pianística tiene una textura de melodía acompañada que puede decirse, evoca un fragmento guitarrístico, por la manera en que se articulan figuraciones con puntillo, en las que sobresalen saltos de terceras descendentes y acordes arpegiados que conducen primero a una semicadencia sobre el acorde de dominante y luego a una cadencia evitada al sexto grado.

El ambiente tonal elegido para este tempo andante que requiere la milonga campera, es típico del estilo guastaviniano de raíz folclórica. Recurre una vez más a una tonalidad menor (Sol menor), alude muy brevemente a tonalidades vecinas como la subdominante (Do mayor) y "colorea" los giros cadenciales de dominante-tónica con la evocación clara del modo frigio, lo cual es característico de la melódica criolla según lo estudiara Gerardo HUSEBY (2002-2003, p.97-114). (Ex.2, c.13-14)

La articulación de las ideas en las estrofas de cuatro versos se realiza cada dos compases, entrando cada una de ellas en forma anacrúsica o tética según lo requiere la adecuada acentuación de las palabras. El ajuste texto-música, como en la milonga campera, es silábico. El acompañamiento en estas estrofas, que el autor indica ejecutar en forma monótona, recurre a un ostinato de dos semicorcheas-corchea sobre cada tiempo, asimilable totalmente a las convenciones de la milonga. Dispone además las estructuras acórdicas a la manera del acompañamiento guitarrístico que habitualmente sigue al punteo en ese género (Ex.3). ${ }^{18}$ Solo pierde su isocronía hacia el final de la segunda y de la cuarta cuartetas, cuando Guastavino desea remarcar el climax del trozo permitiéndole al canto protagonizar, en tempo más rubato, los pasajes que permiten al oyente completar la audición de las frases, encontrando la simetría de las partes. 

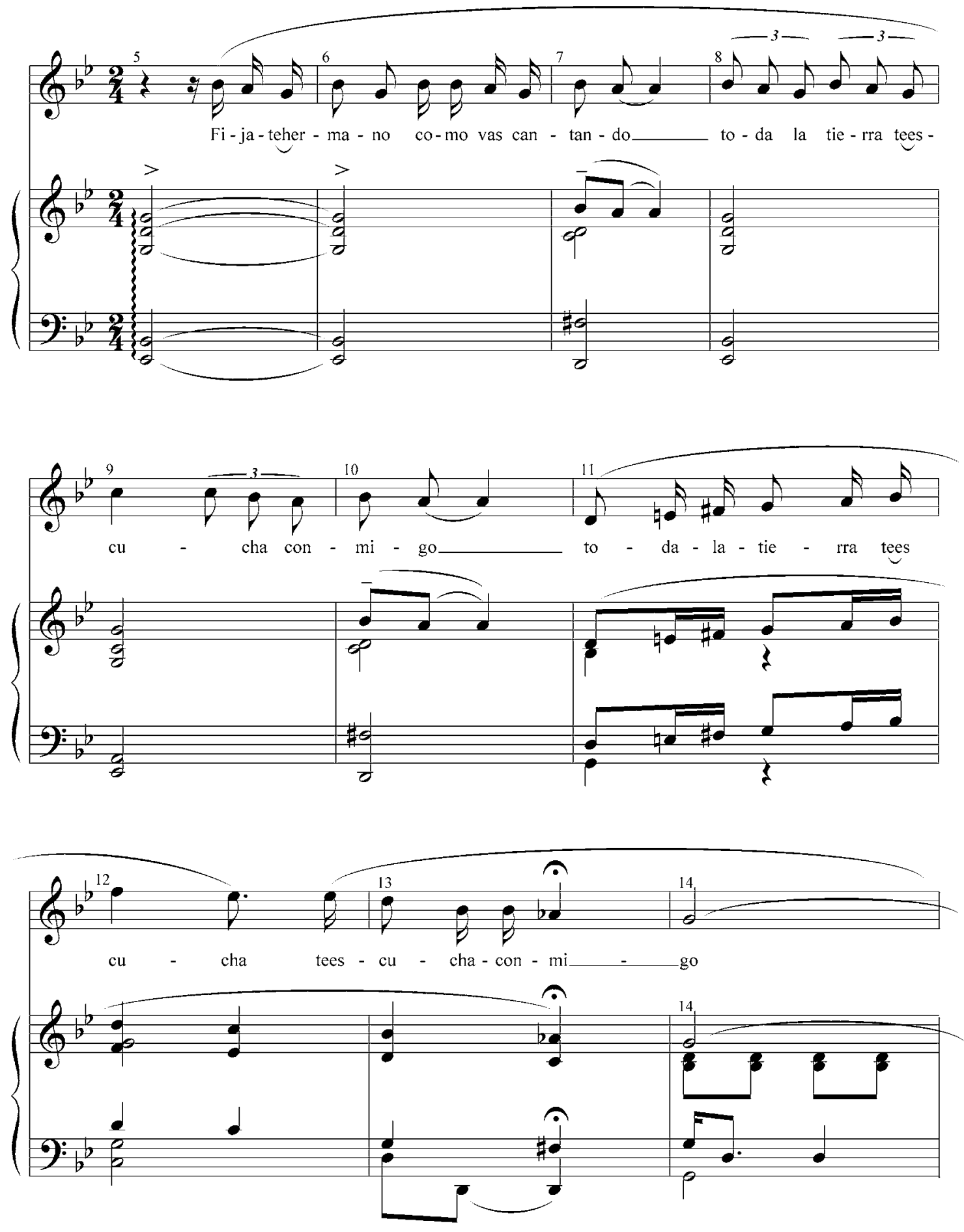

Ex.2. Lima Quintana-Guastavino, Hermano. C.5-14 (Warner Chappell Music).

Elementos de la cifra: presencia del modo frigio

\section{5- La versión de Mercedes Sosa}

La revista Primera Plana recogió ideas muy claras de la cantante tucumana respecto del contenido del disco Hermano. "El folklore de hoy debe dirigirse al hombre y no al paisaje." "Hay que lograr la unión que la geografía obstaculiza." "Eso no se logrará sino hablándole al hombre: la miseria y el dolor son los mismos en todas partes." Frases enfáticas, cargadas de humanismo, permitieron al comentarista concluir, de cara al futuro, que Hermano "desmiente, de una vez, que la tradición cantada sea una pieza de museo para exclusivo uso de investigadores y antropólogos".

Sergio PUJOL (2002, p.286-287) afirma que es Mercedes Sosa quien sintetiza los aportes de la ola folclórica de los años 60 y quien con "su voz grave y despojada, se convirtió en el instrumento más virtuoso del boom." Cierto es que fue una de las figuras que resultó más seguida y aclamada por el público, pero resulta difícil afirmar sin pruebas 
fehacientes que su éxito haya sido más franco que los de Atahualpa Yupanqui o Eduardo Falú. De lo que sí no caben dudas, es que ha sido la voz femenina más solicitada.

Los momentos culminantes de la carrera de Mercedes Sosa en que se da la aparición del disco Hermano vienen encuadrados del siguiente modo: unos meses antes, la grabación del Romance de la muerte de Juan Lavalle (de Eduardo Falú y Ernesto Sábato) y la aparición del disco Yo no canto por cantar ya mencionado; unos meses después, la primera gira europea con Ariel Ramírez, Jaime Torres y Los Fronterizos, de la cual surgió la propuesta de Ramírez para ser la intérprete de su ciclo Mujeres Argentinas. Hermano contiene doce canciones. La primera y la última pertenecen a Lima Quintana. Podría decirse de ma- nera aproximativa que las que más han perdurado de este álbum en cuanto a circulación hasta la actualidad, serían la segunda y la sexta de aquel disco. Véase el contenido completo en el Ex4.

Una recorrida rápida por el listado de personas citadas en la tabla, arroja hasta donde se ha podido indagar la siguiente posible red de cooperaciones, de ninguna manera excluyente ni definitiva: Tejada Gómez, la intérprete y Matus son fundadores del Nuevo Cancionero. ${ }^{21}$ Lima Quintana se integra a ese movimiento al trasladarse los anteriores tres a Buenos Aires. Moncho Miérez estuvo ligado a la editorial Lagos y fue el guitarrista acompañante de Mercedes Sosa durante los primeros años en que ella se estableció en Buenos Aires y quien le ense-

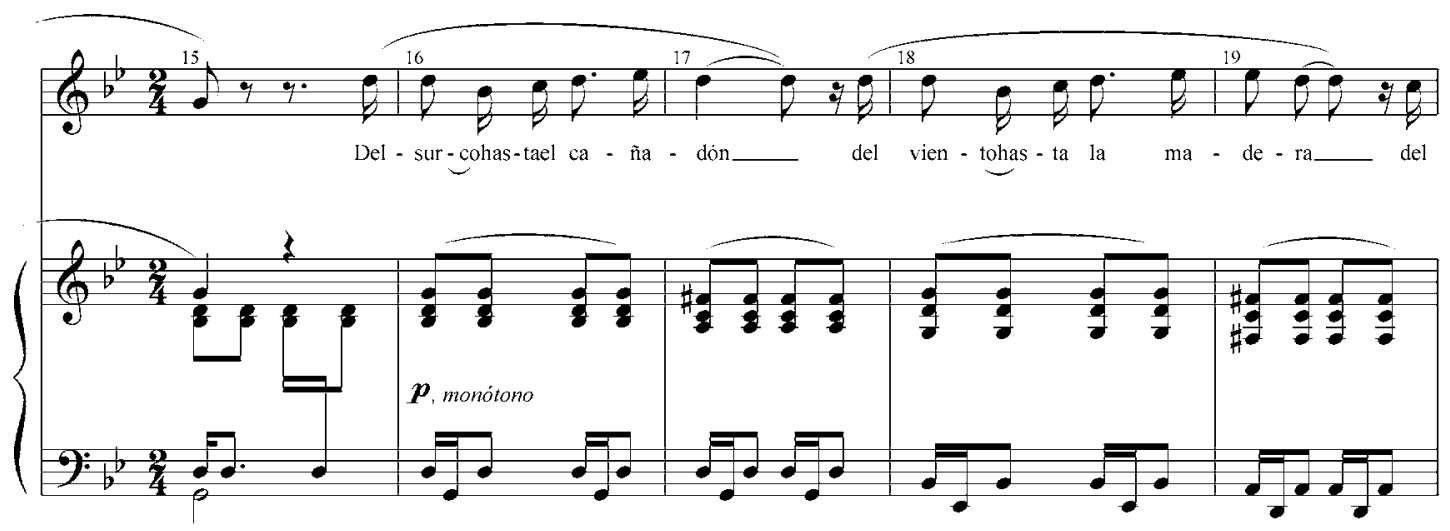

Ex.3. Lima Quintana-Guastavino, Hermano. C.15-19 (Warner Chappell Music). Elementos de la milonga.

\begin{tabular}{|c|l|l|l|}
\hline Pista & Título & Poeta & Compositor \\
\hline 1 & Hermano (Canción) & Hamlet Lima Quintana & Carlos Guastavino \\
\hline 2 & Chacarera del 55 (Chacarera) & José y Rafael Núñez & José y Rafael Núñez \\
\hline 3 & Para mañana (Zamba) & José R. [Moncho] Miérez & José R. [Moncho] Miérez \\
\hline 4 & Pescadores de mi río & Chacho Müller & Chacho Müller \\
\hline 5 & Coplera del viento (Canción) & Armando Tejada Gómez & Oscar Matus \\
\hline 6 & Quiero ser luz (Zamba) & Daniel Reguera & Daniel Reguera \\
\hline 7 & Zamba del chaguanaco & Antonio Nella Castro & Hilda Herrera \\
\hline 8 & Tristeza (Tonada) & José y Rafael Núñez & José y Rafael Núñez \\
\hline 9 & La bagualera (Baguala) & Ariel Petrocelli & Ariel Petrocelli \\
\hline 10 & Palomita del valle (Vidalita) & Ernesto Sábato & Eduardo Falú \\
\hline 11 & Monte chaqueño (Canción) & Ángel [Kelo] Palacios & Ángel [Kelo] Palacios \\
\hline 12 & Esto azul (Cueca) & Hamlet Lima Quintana & Hamlet Lima Quintana \\
\hline
\end{tabular}

Ex.4.Contenido del disco Hermano. Mercedes Sosa. (Philips, 82122 PL.1966) 
ñó la Zamba para no morir.22 Eduardo Falú interpretó la música instrumental de Guastavino, adaptó y grabó algunas de sus canciones, compuso obras en colaboración con él, fue su alumno, asesor y amigo. Ariel Petrocelli, el autor de la popular Cuando tenga la tierra, ${ }^{23}$ publicó toda su obra en la editorial Lagos. Kelo Palacios fue durante nueve años el arreglador y guitarrista de Mercedes Sosa. Hilda Herrera, pianista cordobesa, publicó también su composiciones en la editorial Lagos.

El disco Hermano apareció a la venta en noviembre de 1966. En la revista Primera Plana se lo publicitaba junto a otras novedades discográficas de la música de raíz folclórica argentina como Bienvenido Falú, La Rioja en la sangre de Chito Zeballos y El grito macho de Horacio Guarany. ${ }^{24}$

El papel predominante de Mercedes Sosa en el ámbito de la canción popular en aquellos tiempos quedó claramente expresado en la calificación de "máxima sacerdotisa del cancionero de provincias" con que Primera Plana describió su éxito en los días previos al Festival de Cosquín de 1967. En concordancia con los conceptos de Confirmado mencionados más arriba, el comentarista no pudo dejar de resaltar lo 'difícil' que resultaba, desde la recepción, ese repertorio. "Es difícil trabar amistad con ese grito duro y auténtico, con ese estilo que parece desmañado pero que proviene de una prolija maceración." ${ }^{25}$

Acaso la voluntad de la cantante, y/o de sus asesores o empresarios, por querer desarrollar un estilo autorizado, válido, que sirviera "para decir cosas importantes", haya tenido que ver con la elección de Hermano para dar nombre a su disco y con la ubicación de la canción en la pista inicial. No deja de ser probable que este 'folclore' arduo, que intentaba apartarse del "puro documento" -como dice el comentarista de Confirmado en el artículo que se ha citado al comienzo de este trabajo- haya decidido recurrir a Guastavino por ser un creador con una trayectoria académica previa, como manera de convalidar su propio estilo. ${ }^{26}$

En cuanto a la versión que grabó Mercedes Sosa, se encuentra acompañada totalmente con guitarra. La guitarra realiza una introducción de acordes arpegiados sobre ritmo de milonga que giran en torno a las funciones de tónica, dominante y dominantes secundarias arribando, hacia la entrada de la voz, al acorde de tónica y no hacia la cadencia rota que Guastavino escribió en la partitura pianística. Una melodía apenas esbozada, cómoda a las posiciones de esos arpegios en la guitarra, reemplaza a la original en la introducción. La solista recita, en vez de cantar, los dos primeros versos, sobre acordes arpegiados en la guitarra. Canta a continuación, en forma casi libre, la repetición del segundo verso. Luego, en las cuartetas octosílabas, entona la melodía -acompañada por la guitarra- respetando la mayoría de las alturas y acentuaciones, pero ajustando la rítmica a su peculiar, atractiva, manera de expresión. Al terminar las cuarte- tas, el guitarrista vuelve a intervenir con el mismo pasaje introductorio, cantando esta vez la solista la melodía escrita, en vez de recitar el texto. ${ }^{27}$ Para finalizar, la guitarra agrega un brevísimo postludio individual solísti$\mathrm{co}$, antes del cierre de los dos versos finales y adiciona todavía dos compases y un acorde, luego que concluye el texto. La versión responde a todas las convenciones requeridas por el género.

\section{6- Miedo, censura encubierta}

Iván Cosentino, conocido editor de discos en Argentina, sugirió una reducción en la circulación de la música de raíz folclórica desde mediados de la década de $1970 .^{28} \mathrm{Sin}$ duda, ello se enmarca en el ya bien estudiado contexto político-cultural de la última dictadura militar del siglo $X X$ argentino que, como es sabido, sentó sus bases en métodos de censura de variados tonos e intensidades.

La época no fue propicia entonces ni para la difusión de la canción folclórica en general ni tampoco, para la difusión musical de Guastavino. ${ }^{29}$ La información recogida en las entrevistas revela que hubo un retraimiento obligado en quienes producian, interpretaban, editaban, grababan, distribuian y vendian los productos artísticos del repertorio de raíz folclórica. La autocensura debida al miedo, que bien puede entenderse como una censura encubierta, ocasionó lo que alguno de nuestros entrevistados calificó como un "desbande", esto es, la desintegración de aquel mundo, de aquellas redes de cooperación que antes funcionaran de manera dinámica, creativa y eficaz. Lo sucedido con el mundo de la Nueva Canción en Argentina es lo que Hernán INVERNIZZI y Judith GOCIOL (2003. p.73) describen como una "falta de referencias, un desconcierto [que impide] hacer planes coherentes, dificulta las reacciones meditadas y solo puede producir miedo y autocensura". ${ }^{30}$

En tal sentido, Hamlet Lima Quintana, Armando Tejada Gómez, Norberto Ambrós, Horacio Guarany, Mercedes Sosa, luego de varias amenazas y algún atentado, debieron partir por varios años hacia el exilio. ${ }^{31}$ Ariel Petrocelli optó retraerse trasladándose, en las sombras de una situación casi de clandestinidad, a alguna provincia argentina. ${ }^{32}$ Iván Cosentino soportó allanamientos y citaciones intimidatorias. ${ }^{33}$ Carlos Alonso, el artista plástico que ilustró varias portadas de la colección de partituras de Lagos denominada "Canción Estampa", sufrió la desaparición de su hija y se exilió en España. ${ }^{34}$ Rómulo Lagos, por su parte, vio decaer su empresa ante la imposibilidad de ofrecer al público el material considerado "riesgoso". 35

\section{7- Epílogo. Hacia las salas de concierto}

Guastavino optó en aquellos años por el silencio. Un silencio explicable en una mentalidad como la suya, aunque se ha hablado aquí de vinculación y no de pertenencia; un silencio que, de no ser por algunas escasas producciones posteriores de fines de la década de 1980 y principios de la siguiente, lo apartó ya definitivamente de la composición. 
Pero su silenciamiento local dio paso al progresivo esparcimiento de su música por el resto del mundo. Redescubierta por cantantes del ámbito culto, Hermano circula desde hace aproximadamente cinco lustros como canción de cámara, fiel en un alto porcentaje a la partitura escrita por el autor y a la edición de Lagos, bajo las convenciones ahora, de la música académica. Perdió así la cualidad primeramente militante, que le otorgara el timbre vocal inconfundible y la manera enfática de transmisión, propios del estilo interpretativo de Mercedes Sosa. ${ }^{36}$ Grabada por el baritono argentino Marcos Fink acompañado al piano por Luis Ascot circula, en los globalizados tiempos actuales, dentro de las convenciones venerables e institucionalizadas del lied. ${ }^{37}$

\section{Referencias bibliográficas}

ARETZ, Isabel. El folklore musical argentino. 3a edición. Buenos Aires: Ricordi, 1970.

BECKER, Howard S. Los mundos del arte. Sociología del trabajo artístico. (Traducción de Joaquín Ibarburu). Bernal (provincia de Buenos Aires): Universidad Nacional de Quilmes, 2008. [Original: Art Worlds. Berkley: University of California Press, 1982].

BUCH, Esteban. The Bomarzo Affair. Ópera, perversión y dictadura. Buenos Aires: Adriana Hidalgo, 2003.

CARRASCO PIRARD, Eduardo. "Canción popular y política", Rodrigo Torres (ed.) Música popular en América Latina. Santiago de Chile: IASPM-FONDART, 1999, p.62-70.

CORRADO, Omar. "Música culta y política en Argentina entre 1930 y 1945: una aproximación", Música e Investigación 9. Buenos Aires: INM, 2001, p.13-33.

GARCIA, María Inés. Tito Francia y la música en Mendoza, de la radio al Nuevo Cancionero. Buenos Aires: Gourmet Musical Ediciones, 2009.

GONZÁLEZ, Marcela. "Carlos Guastavino. La poesía del encuentro", Ismos, arte y música nº 1, Oviedo (España): Vicerrectorado de estudiantes, 1999, p.71-86.

GUARANY, Horacio. Memorias del cantor. Casi una biografía. Buenos Aires: Sudamericana, 2002.

HUSEBY, Gerardo, "Presencia del modo frigio en la melódica criolla", Revista Argentina de Musicología 3-4. Buenos Aires: AAM, 2002-2003, p.97-114.

INVERNIZZI, Hernán y Judith GOCIOL, Un golpe a los libros. Represión a la cultura durante la dictadura militar. Buenos Aires: Eudeba, 2003.

LIMA QUINTANA, Hamlet. Para no morir. Buenos Aires: Torres Agüero, 1986.

LIMA QUINTANA, Hamlet. Los referentes (Una historia de amistad), Buenos Aires: Torres Agüero, 1994.

MANSILLA, Silvina Luz. La obra musical de Carlos Guastavino. Circulación, recepción, mediaciones. Buenos Aires: Gourmet Musical Ediciones, 2010.

PLESCH, Melanie. "La música en la construcción de la identidad cultural argentina: el topos de la guitarra en la producción del primer nacionalismo", Revista Argentina de Musicología 1. Córdoba (Argentina): AAM, 1996, p.57-68.

PORTORRICO, Emilio. Diccionario biográfico de la música argentina de raíz folklórica, 2a edición. Buenos Aires: el autor, 2004.

PUJOL, Sergio. La década rebelde. Los años 60 en la Argentina. Buenos Aires: Emecé, 2002.

ROMERO, Luis Alberto. Breve historia contemporánea de la Argentina. 2ª edición. Buenos Aires: Fondo de Cultura Económica, 2001.

VILA, Pablo. "Música popular y auge del folklore en la década del '60", Crear en la Cultura Nacional II: 10, Buenos Aires, sept-oct 1982, p.24-27.

\section{Sitio electrónico}

Sitio oficial de Mercedes Sosa: http://www.mercedessosa.com.ar. Último acceso: 10 de marzo de 2009. 


\section{Notas}

1 Agradezco especialmente a María Inés Garcia, Esteban Buch, Emilio Portorrico, Omar Corrado y Melanie Plesch por los comentarios realizados en diferentes momentos a este texto. A Ricardo Jeckel, por su ayuda técnica con los ejemplos musicales.

Una primera versión de este trabajo fue leída en agosto de 2004 en Mendoza (Argentina), en el marco de la XVI Conferencia de la Asociación Argentina de Musicología, co-organizada con la Facultad de Artes y Diseño de la Universidad Nacional de Cuyo. Un desarrollo bastante mayor de esta temática, se encuentra contenido en el capítulo quinto de La obra musical de Carlos Guastavino. Circulación, recepción, mediaciones, libro de mi autoria (Gourmet Musical Ediciones, 2010). Agradezco especialmente a Leandro Donozo por autorizar la inclusión aquí de una parte de ese texto, al momento de la edición de esta revista, aún inédito.

2 Confirmado, 23-6-1966, p.57. El artículo no lleva firma.

3 La expresión shock autoritario pertenece a Luis Alberto ROMERO. El historiador explica que se disolvieron los partidos políticos y se les confiscaron y vendieron todos sus bienes como para confirmar que la clausura de la vida política era irreversible. Se combatió especialmente al comunismo, sobre todo en las universidades públicas. Sobrevino la llamada 'Noche de lo Bastones Largos' y las redes intelectuales y académicas debieron sobrevivir trabajosamente en espacios semi-ocultos, debido a la amplia extensión que alcanzó la censura. (ROMER0, 2001, p.170-171).

4 Fue un disco de larga duración, editado por el sello Philips bajo el nº 82.122.

5 BECKER sostiene que todo trabajo artístico involucra la actividad conjunta de un número de gente y asigna importancia a la red de gente que coopera -y cuyos trabajos son esenciales- en pos de un resultado final de la obra. (BECKER, 1982). Sobre la aplicación del marco teórico a este objeto de estudio véase MANSILLA, 2010.

6 El guitarrista Ramón Miérez lo relata con toda claridad: "Lagos le propone a Hamlet musicalizar sus poemas con Guastavino" (Entrevista con la autora 5-10-2003). A la colección La verde rama, de Lagos, pertenece el libro Cuentos para no morir, de Hamlet Lima Quintana, con prólogo de Armando Tejada Gómez (LIMA QUINTANA, 1994, p.44).

7 Autor de los libros Mundo en el rostro, Pampamapa, en la huella en el sur, Sinfonía de la llanura, Situación personal, Cuentos para no morir, Calfucurá, Los estafados, Declaración de bienes, La breve palabra, Los referentes y El perfeccionista, entre otros. También escribió una biografía del famoso pianista y compositor de tango, Osvaldo Pugliese, en 1990. (PORTORRICO, 2004, p.232-233).

8 No puedo extenderme aqui sobre qué fue el Nuevo Cancionero, pero al menos una breve nota para explicarlo: su actividad, que comenzó a principios de la década de 1960, implicó un proceso de renovación de la canción popular basada en elementos folclóricos y propuso una búsqueda de integración entre los distintos géneros musicales en un afán de innovación en la poesia y en la música. Fundado por los músicos Tito Francia, Juan Carlos Sedero y Manuel Oscar Matus, los poetas Armando Tejada Gómez y Pedro Horacio Tusoli, Mercedes Sosa y el bailarín Víctor Nieto, el movimiento presentó sus objetivos y postulados en un manifiesto que lanzó el 11 de febrero de 1963 a través del periódico Los Andes, en la ciudad argentina de Mendoza (Véase GARCÍA, 2009 y MANSILLA, 2010).

9 Norberto Ambrós, según Iván Cosentino, trabajó también un tiempo como pianista en la Editorial Lagos: "Venian los intérpretes, los cantantes, él tocaba. ¡Nos complementábamos muchísimo! éramos muy jóvenes ambos." (Entrevista con la autora, 1-3-2004).

10 Este disco, de mayo-junio de 1966, es el primero editado por Philips. Además de la Zamba para no morir contiene: Canción del derrumbe indio (Figueredo-Iramain), Los inundados (Aizemberg-Ramírez), La solitaria (M. Miérez), Zamba azul (T. Gómez-Tito Francia), Tonada de Manuel Rodríguez (Neruda), Zamba del zafrero (T. Gómez-Matus), Quena (A. Aguirre), Mi canto es distancia (Matus-Paeta), Chayita del vidalero (R. Navarro), Canción para mi América (D. Viglietti) y Zamba del riego (T. Gómez-Matus). El título alude a una copla popular muy difundida con la cual comienza la canción Manifiesto de Víctor Jara, el canta-autor chileno torturado y asesinado después por la dictadura de Augusto Pinochet, en septiembre de 1973: "Yo no canto por cantar/ ni por tener buena voz/ canto porque la guitarra/ tiene sentido y razón."

11 Coincido con esta afirmación de Pablo Vila, basada en datos estadisticos de ediciones de partituras (VILA, 1982, p.24-27). Hermano contiene un aire de milonga campera. A diferencia de la zamba, el género milonga requiere mayor destreza instrumental en el acompañamiento con guitarra, lo que no lo hace tan fácilmente accesible a cualquier aficionado.

12 Emilio Portorrico tuvo la gentileza de puntualizarme el hecho de que el poema Hermano es preexistente a la musicalización de Guastavino. Data de 1960 y según explica Lima Quintana, habría tenido antes una música de él, pues fue "cantado personalmente con música improvisada en Lima, Perú" (LIMA QUINTANA, 1986, p.24).

13 Diferente en cuanto a los propósitos poéticos de los artistas del Nuevo Cancionero pero en la misma línea temática, Horacio Guarany incursionó también en estos contenidos en su conocidísima y después muy censurada Si se calla el cantor. Sobre las alternativas que debió pasar durante los años de la dictadura militar, que abarcaron desde atentados directos a su casa, hasta prohibiciones, amenazas, Ilamadas telefónicas, recomendaciones y exilio, véase: GUARANY, 2002.

14 Dicha sensibilidad puede verse en la elección de la poesía "social" de Gabriela Mistral (Piececitos, por ejemplo: Piececitos de niño/ azulosos de frío/ ¿cómo os ven y no os cubren? Dios mío...). En cuanto a la defensa de la libertad de expresión, estuvo el caso de su opinión favorable a Ginastera cuando la prohibición de su ópera Bomarzo en el teatro Colón, expresada a la revista Gente, en pleno Onganiato (BUCH, 2003, p.128).

15 Lamentablemente no se explaya más, pero habla de "prohibiciones y censuras oficiales y otras no tanto". Es un tópico que aún falta profundizar el de las censuras oficiales a sus libros. Comenta que el sello grabador "Azur", dirigido por Virgilio Expósito y Jorge Montemurro, que difundia música folclórica, sufrió allanamientos durante el gobierno de Onganía, aunque salvó el material. (LIMA QUINTANA, 1994, p.32 y 36)

16 Se denomina asi a la música practicada en las zonas rurales del sur de la región pampeana de Argentina.

17 De la cifra tiene el ajuste silábico, la interpretación en estilo rubato con finalidad expresiva, y el diálogo entre canto y piano, que en ese género folclórico se realiza con la guitarra (ARETZ, 1970, p.152-156). Agradezco a Ricardo Mansilla su sugerencia sobre la presencia de la cifra en esta canción.

18 Guastavino adhiere asi al primer estilo nacionalista, caracterizado por este tipo de referencias a la guitarra en obras pianísticas. Sobre el particular véase PLESCH, 1996, p.57-68.

19 Primera Plana, n² 214, 31-1-1967, p.68.

20 Como se sabe, este disco contiene canciones dedicadas a mujeres destacadas de la cultura argentina, entre otras, la célebre zamba Alfonsina y el mar con texto de Félix Luna, en alusión a la trágica muerte de la escritora Alfonsina Storni.

Sitio oficial de Mercedes Sosa: http://www.mercedessosa.com.ar/marcosmaster.htm. Último acceso: 10-3-2009.

21 Oscar Matus, recuérdese, estaba entonces casado con Mercedes Sosa.

22 La Zamba para no morir fue editada por Lagos en la colección "Canción Estampa", con ilustración del pintor boliviano Raúl Lara.

23 Una de las canciones muy censuradas durante la dictadura militar, según Moncho Miérez. Respecto del tema de las recomendaciones realizadas durante el Ilamado Proceso de "Reorganización Nacional" acerca de la circulación de este repertorio, Alicia Lagos, hija del editor Rómulo Lagos, nos dijo: "en el ámbito musical, hubo listas... de intérpretes, de autores incluso... de temas, que no podian difundirse. $Y$ algunos de esos eran los publicados por nuestra editorial." (Entrevista con la autora, 10-10-2003).

24 Primera Plana, n 204, 22-11-1966, p.87

25 Primera Plana, n² 214, 31-1-1967, p.68. 
26 Confirmado, 23-6-1966, p.57. Mercedes Sosa dice: "en el otro extremo [...] están los que piensan que no importa cómo se diga, con tal de decir cosas que duelan: todos los días recibo canciones de tipo decididamente panfletario, sin ningún valor artístico, que no tengo más remedio que tirar al canasto".

27 Aunque no aparece indicado, Miérez nos dijo que quien interpreta el acompañamiento guitarristico en la canción Hermano, es él. (Entrevista citada). 28 "Con la llegada de estos delincuentes, el género que más sufrió fue el folclore...", nos dijo Cosentino (Entrevista citada).

29 En un artículo aparecido en Clarín, Sergio PUJOL destaca este hecho, haciendo un poco de historia personal. Afirma que: "si bien la dictadura quemó más libros que discos y persiguió más a la literatura que a la música, la censura y la intimidación sitiaron aquella producción musical que el régimen consideraba "disolvente". El folclore, por ejemplo. [En Buenos Aires] los servicios rastrillaban las disquerias del centro y los barrios en busca de discos de Mercedes Sosa, el Dúo Salteño, Víctor Heredia, Horacio Guarany y Los Andariegos." (18-3-2006, Revista "Ñ" del diario Clarín).

30 Véanse los fundamentos del General de Brigada José Antonio Vaquero expresados mediante nota, al Gral. de Brigada Eduardo Harguindegui: la solución "de fondo", dice, está en combatir a la subversión en el ámbito cultural. (INVERNIZZI-GOCIOL, 2003, p.44; énfasis mío).

31 Lima Quintana, Tejada Gómez, Mercedes Sosa y Guarany estuvieron exiliados en España. Norberto Ambrós se radicó en EEUU.

32 No se pudo ubicarlo, pero Cosentino cree recordar que se habia retirado a una estancia en las sierras cordobesas. (Entrevista citada)

33 Cosentino comentó que hacia fines de los setenta, su sello discográfico Qualiton-Fonema, sufrió un allanamiento por la edición de un disco llamado Canciones para hacer pensar a los chicos, que fue considerado inapropiado. La requisa, con claro carácter intimidatorio, fue realizada por la marina, durante las horas de la noche. Después, él debió asistir durante varias semanas, todos los dias al Ministerio del Interior a dar explicaciones sobre su trabajo y sobre sus planes comerciales futuros: "Entonces... me hacian entrar alli [...] me tenian en un escritorio dos horas, sin hablarme, sin atenderme, ni nada. Después venía uno y me decía: "Y qué hizo Ud...?" "Yo?, nada que ver", contestaba. Y era siempre lo mismo, siempre lo mismo." Comentó que no fue obligado a cerrar, pero que la presión fue muy grande: "si nos evadiamos, nos buscaban por todos lados [...] No nos cerraron, ni nada. De hecho, trabajábamos. Pero claro, todos los dias, iba allá Iván.... a 'poner la carita' [...]. No tenía nada para decir. No pertenecía a ninguna organización [...]. No la pasamos muy bien. Secuestraron todos los discos ésos, de todas las casas de discos, los quemaron... solo pudimos salvar creo que 20..." (Vico Ciliberti, el autor del disco infantil, se exilió en Italia).

34 Alonso, muy ligado a la gente de la editorial Lagos y a los artistas del boom del folclore, perdió a su hija Paloma.

35 Alicia Lagos expresó: "Yo no tengo noticias de que mi papá haya tenido problemas personalmente [...] sé que fue una época de mucho cuidado, de un perfil muy bajo para trabajar [...] no se puso a disposición del público todo el material que se consideraba censurado. Se guardó. Armando Tejada Gómez, César Isella, Ariel Petrocelli, Horacio Guarany... Ésos eran nombres que habia que 'evitar', de alguna manera." (Entrevista citada).

36 Agradezco a Esteban Buch esta observación, que creo aguda y precisa.

37 La grabación se realizó en Ginebra. Radicado desde mediados de la década de 1990 en Eslovenia, Fink incluye a menudo en sus recitales obras de Guastavino. (CD VEL 1059- Cascavelle, Ginebra/ CH 1996). Una grabación reciente es la de Víctor Torres, acompañado por Dora Castro al piano. (IRCO y Universidad Nacional del Litoral, 2008. IRCO 337).

Silvina Luz Mansilla (Villa Mercedes, San Luis, Argentina, 1962). Doctora en Artes por la Facultad de Filosofía y Letras de la Universidad de Buenos Aires. Licenciada y Profesora Superior de Música, especialidad Musicología por la Universidad Católica Argentina y Profesora de Piano, graduada del Conservatorio Nacional de Música "Carlos López Buchardo". Docente en la cátedra "Música Latinoamericana y Argentina" de la Universidad de Buenos Aires, dicta también "Historia de la música argentina" en la Facultad de Artes y Ciencias Musicales de la Universidad Católica Argentina. Autora de artículos referidos a música académica argentina del siglo $\mathrm{XX}$, tutora del equipo de investigación La música en la prensa periódica argentina (UBACyT F-831), ha sido becaria de la Dirección General de Relaciones Culturales y Científicas, de España (2000) y del Fondo Nacional de las Artes, de Argentina (2003). Colaboradora del Diccionario de la Música Española e Hispanoamericana, publicado en Madrid por la SGAE, ha obtenido subsidios del Fondo Metropolitano de Cultura del Gobierno de la ciudad de Buenos Aires (2005) y de la Fundación suiza Familie Vontolben (2007). 